\title{
UNOS DATOS SOBRE JOVELLANOS Y TRES CARTAS DE 1812
}

\section{Gregorio C. Martin}

De todos es bien sabido que Jovellanos gozaba de gran prestigio entre los componentes de la Junta Central, y que sus ideas ejercieron gran influencia en las Cortes de Cádiz. No es extraño entonces que D. Carlota Joaquina, hermana de Fernando VII y aspirante a sucederle cuando estaba prisionero de Napoleón, quisiera atraer a Jovellanos para que figurase entre sus partidarios. Con este objeto escribió a él y a Francisco Saavedra en noviembre de $1808 .^{1}$

Jovellanos respondió con cortesía, pero dejando bien claro que toda ayuda que el pueblo español recibiera de Carlota era algo que había merecido de antemano, porque se lanzó a defender para un rey el trono que éste había abandonado. Gracias a eso ella podía reclamar sus derechos. Igualmente, si él (Jovellanos) era ahora honrado por la hija de Carlos IV, había sido en otro tiempo injustamente perseguido por el padre. Una cosa compensaba la otra.

La carta dice así:

\section{Señora.}

Enmedio [sic] de la angustia en que nos tiene el cautiverio de nuestro buen Rey, augusto hermano de V.A.R., y la horrible guerra que su perfido opresor hace á la Nacion Española, justa y noblemente empeñada en defender los derechos del Trono, y en conservar su independencia, há sido para todos los buenos Españoles de gran consuelo, $y$ del agüero mas feliz, ver á V.A.R. tan generosamente dispuesta á auxiliar nuestros esfuerzos, protegiendo una causa tan justa, $y$ en cuyo triunfo se halla tan personalmente interesada. Pero Señora, si nosotros recibimos esta preciosa oferta de proteccion con la mas pura gratitud, tenemos tambien la satisfaccion de habernos anticipado á merecerla: pues que jurando defender los derechos de nuestro Soberano hemos procurado preservar el q? V.A.R. tiene a succederle [sic] en falta de sus augustos hermanos. Dignese, pues, V.A.R. de recibir los sentimientos de respeto $y$ confianza con que todos correspondemos $\dot{a}$ su bondad; pero dignese de recibir mas señaladamente los mios, que no siendo por ningun titulo acreedor á las particulares honras con que V.A.R. se há dignado distinguirme, debo mirarlas como una mas ilustre prueba de la bondad de su augusto corazon que acaso há querido indennizar con distincion tan honrosa, las humillaciones y males con que una injusta persecucion aflixio [sic] los ultimos siete años de mi vida. Por lo mismo Señora los que me restaren serán empleados en acreditar constantemente á V.A.R. mi sincera gratitud, asi como mi amor, y mi veneracion á su augusta Persona: la qual conserve y ensalse [sic] el Cielo con la mayor prosperidad, como lo ruego en Sevilla 24 de Abril de 1809.

Señora

Gaspar Melchor de Jovellanos ${ }^{2}$ 


\section{Señona.}

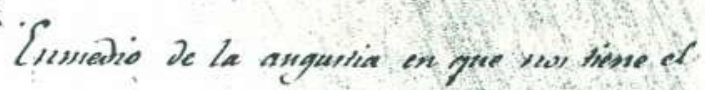
施成

(P.B.

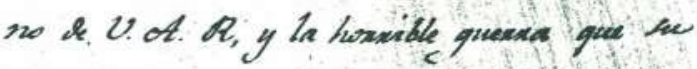

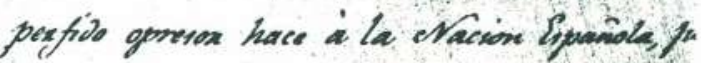

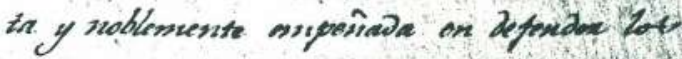

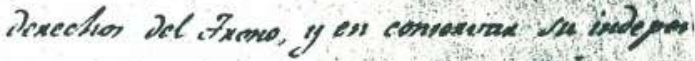

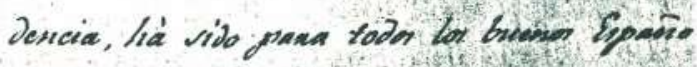

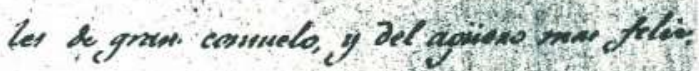

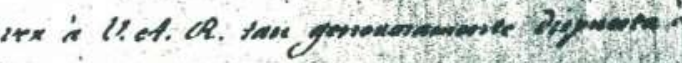

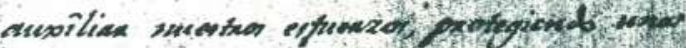

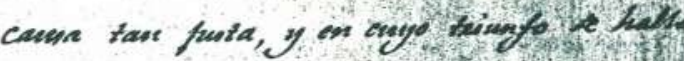

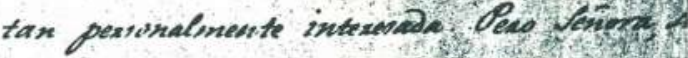

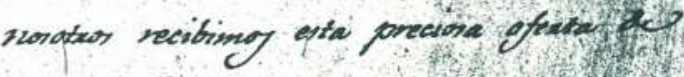

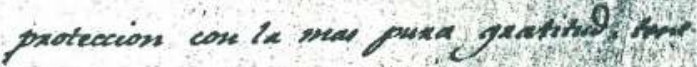

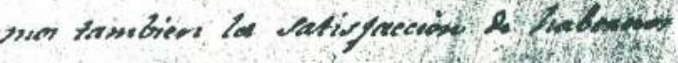

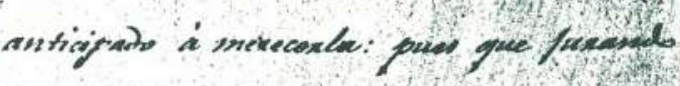

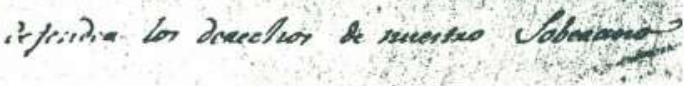




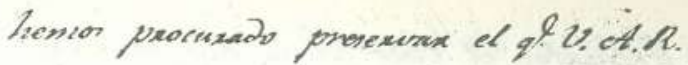

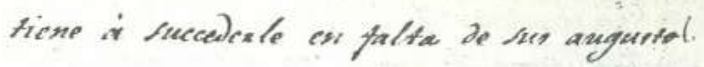
kexmasuor. Dignere, pues. U. AT.CR \& reos bix lor vestimientor \& impeto y conficanal con que todos coxresporidemos à ho bondalife no Jignere \& recibiz mas Lisidadaneaste fo,

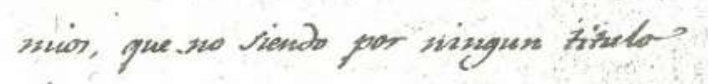

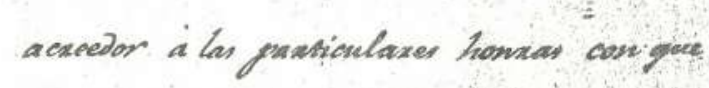
V. A.U. Le ha dignads dirtinquinume, debo mixantas como unie mas iluosire goweda?

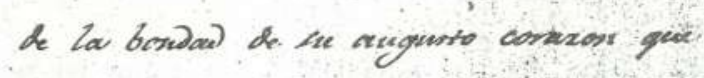

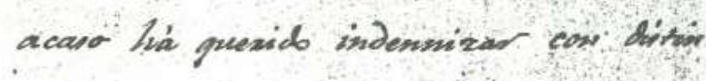
cion tase honxora, Ial humillacione? males con qui una infusta pesseeveson

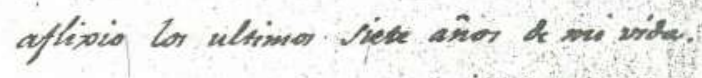
Din lo mivmo lesiona lor que neve resta.

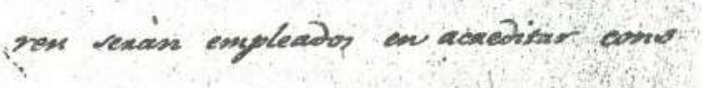 twotemente \& $V$ of OA ms inpere gop}

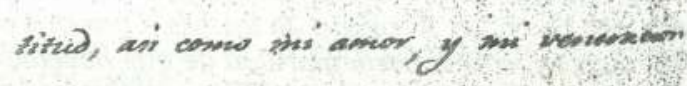

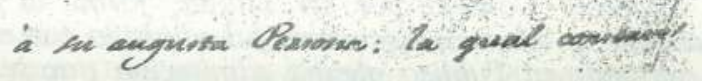




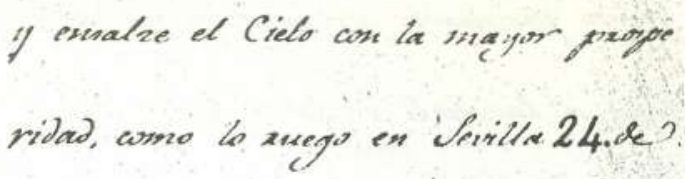

Abril de1809.

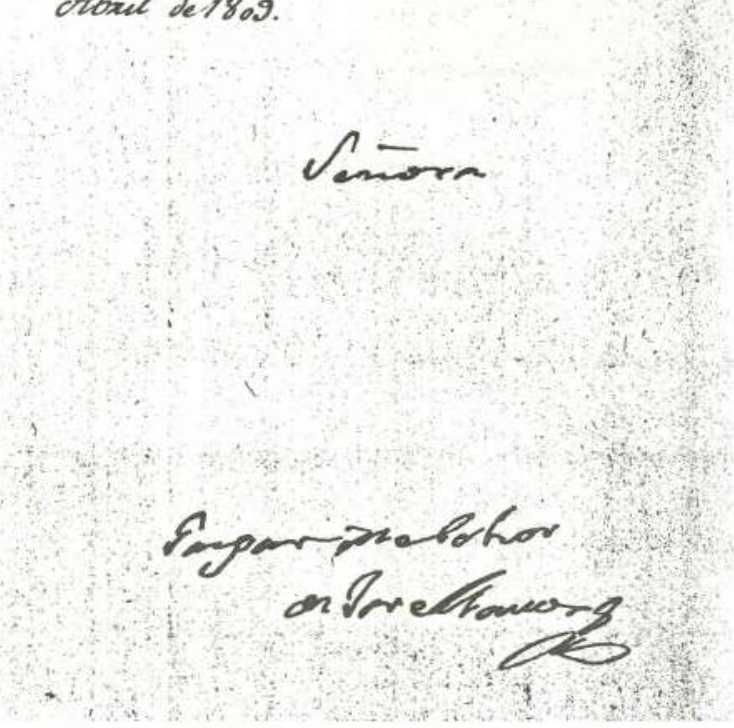

La siguiente comunicación, redactada en términos tan sensibleros y pedantes que no necesita comentarios, es buena prueba de la razón que tenía Jovellanos al quejarse de injustas persecuciones:

\section{M.P.S.}

Una Cituacion la mas lamentable en el superior grado de indigencia, producida de la temeraria oposicion del Ministro Jovellanos al RL. Cuerpo de Guardias de Corps, me obliga a molestar la atencion de V.M., confiado en su magnanimo Corazon, y en algunos particulares, $y$ recomendables meritos.

Al seguiente dia de haver nacido el Serenisimo $S .^{\text {or }}$ Infante Dn. Franco de Paula tuve el honor de besar la mano al Rey Ntro. S. ${ }^{\text {or }}$ (que Dios gue.) para la Compañia Flam. ${ }^{\text {ca }}$ donde é continuado con la mayor conducta, y exactitud de lo que informarán mis xefes; pero haviendo anteriorm. ${ }^{\text {te }}$ seguido la carrera literaria en la Universidad de Sevilla la continué al mismo tiempo sin perjuicio la una de la otra, manifestando singular amor al Rl. Cuerpo, y aplicacion a la Judicatura, por lo que me incorporé en la Academia de $S^{n}$ Felipe el Rl. y posteriormente me recivi de Abogado de los Rls. Consejos como consta por la adjunta relacion, con la particularidad de que haviendose opuesto el Real y Supremo Consejo por ser Militar, formé el competente recurso, que gané, y en su consecuencia fui admitido con mi completo uniforme, causando al Publico alguna admiracion por ser el primer 
exemplar, por cuya reunion de carreras me lisonjeaba serian felices tanto mis Padres, como yo con mis hermanos, quando en la noche del dia tres de Marzo del año pasado de 96 viniendo mis Padres a tomar posesion de la Administracion de Tabacos y Millones del Puente del Arzobispo, bolcó el coche, en que caminaban, del que sacarcn a mi Padre cadaver sin haver recivido la Extrema-Uncion y mi Madre insultada del que no bolvio hasta las doce de la misma, por cuya tragica muerte quedaron a mi cargo mi Viuda Madre, $y$ dos hermanos sin mas auxilio que el sueldo que disfrutaba por Guardia.

Un hijo amante de su Familia, poseido de los mayores sentimientos de Honor, y creido algo proporcionado para salir con colocacion suficiente á sostenerla, no pudo dejar de preferir la carrera literaria, que es la que prestaba mayores ventajas, y en la que su Difundo Padre havia invertido todo su Patrimonio, por lo que el año proximo pasado solicité una de las Fiscalias de Chile y Caracas para las que fui recomendado muy particularmente por el Sargento Mayor Principe de la Paz, no por capricho, como juzgó Jovellanos, y si por estar enterado de mis sircunstancias, cunducta, aplicacion, $y$ principalmente por constarle la indixencia que con mi familia padecia, de la que prescindió dho. Ministro, dejandome sin alguna de las Plazas que se despacharon en el Rl. Sitio de Aranjuez.

No contento con esto haviendo ocurrido despues varias vacantes fui recomendado del mismo por el Sargento Mayor Marques de Ruchena por las mismas causas haciendolo tambien personalmente mi Capitan Principe Masserano, cuyas recomendaciones, circunstancias, y situacion han sido de ningun valor, y efecto para el tal Jovellanos por seguir su sistema, Antagonista declarado de los Militares, hasta el caso de negarme todo derecho a Plaza Togada diciendome: no me lisonjease con vanas esperanzas, sin que mi demasiada humildad pudiese hablandar un Corazon tan empedernido contra mi Justicia, siendo solo su animo sacrificarme, para lo que me hizo presentarle un Memorial sin pedir cosa determinada con el imprudente objeto dicho, lo que logró luego que me despedi en la noche del veinte y uno de Junio pasado, despachandome al proximo Domingo con la Asesoria de Guayaquil Reyno del Perú, y con la miserable dotacion de cuatro cientos pesos, privandome del sueldo de Guardia, y demás ventajas a la Acesoria, lo qe. no pude evitar por carecer de toda noticia para precaver los perjuicios que se me ivan a inferir por tan inesperada colocacion.

Es de advertir Pod. ${ }^{\text {sa }}$ S. ${ }^{\text {ra }}$ protectora de aflixidos que haviendo tomado los devidos conocimientos para emprender su marcha, y la avilitacion necesaria $p^{a}$ el efecto, encuentro que para tomar posesion del empleo gastando la mayor economia necesito de cuatro a cinco mil duros invirtiendo estos en el Flete, Libreria, equipaje y dexar una corta asistencia para mi Familia, cuya cantidad, aun cuando no mediase las actuales circunstancias de Guerra, absolutamente habria quien la diese por deberse esta pagar con la corta dotacion de los cuatro cientos $p^{s}$; por consequencia faltando la avilitacion es moralmente imposible hacer la marcha, siguiendose a esto no disfruto de sueldo hasta embarcarme, ni conservo el de Guardia, por lo que es claro he de perecer con mi Familia.

Para evitar mi ruina he presentado un Memorial al Rey Ntro. Sor. (que Dios gue.) solicitando una de cuatro Plazas vacantes, 
esperando de su Real Piedad y del Magnanimo corazon de V.M. que enterada de quanto llevo expuesto me conceda la Plaza de Bibliotecario Mayor de S. ${ }^{n}$ Isidro, en su defecto una de las dos vacantes en la Rl. Audiencia de la Coruña, o la de Oidor en la Rl. de Buenos Ayres, cuya gracia será del agrado de Dios a quien pido por la Felicidad de VV.MM. $y$ Real Familia para que sean eternos en su mayor Grandeza. $S .^{n}$ Lorenzo, y Nov. ${ }^{r e} 26$ de 98.

\title{
Señora
}

\author{
A L. R. P. De V. M. \\ Jose Calderon y Entrena ${ }^{3}$
}

Carlota Joaquina fue más lejos para atraer a Jovellanos. En diciembre de 1809 le confirió plenos poderes para que la representara, defendiendo sus derechos, ante la Junta Central y las Cortes:

Doña Carlota Joaquina de Borbon Infanta de España,

Princesa de Portugal y del Brasil \&. ${ }^{a} \&^{a}{ }^{a} \&^{a}$

Sepan todos quantos esta mi carta vieren, que por ella otorgo y doy todo mi poder, y quanto sea necesario en derecho, á $D .^{n}$ Gaspar Melchor de Jovellanos; para que representando mi persona y acciones, pueda en mi nombre comparecer ante la Suprema Junta Central Gobernativa del Reyno de España e Indias, ó ante las Cortes, que por Decreto de la misma Junta, expedido en 25 de Mayo, del presente año, deben convocarse por todo el año proximo; $y$ ante ellas promover, instar, pedir, y reclamar, con arreglo á las Leyes $y$ Constituciones de mi Nacion, la justa y legitima posesion de los derechos, que por la desgraciada suerte de mis muy queridos Hermanos, $y$ por Ministerio de la Ley me pertenezcan; sin que por esto pueda entenderse, que en tiempo alguno sea mi intencion ó voluntad, el perjudicar, ni tocar en lo mas minimo la antelacion, y preferencia que tienen mis refiridos Hermanos á la posesion del Trono de España e Indias; la que respeto y reconosco, como el mas alto y sagrado de los Derechos. $Y$ deseando, que por esta mi Carta quede plenamente facultada la persona del expresado D. ${ }^{n}$ Gaspar Melchor de Jovellanos, y se tenga y mire como a mi legitimo representante y apoderado, quiero, $y$ es de mi voluntad, que se tengan aqui por expresas lo mismo que si estubieran escritas, todas las clausulas y requisitos, que de Derecho se requieran para su mas perfecta y completa institucion.

Asi mismo quiero q. ${ }^{e}$ en defecto del expresado $D .{ }^{n}$ Melchor de Jovellanos, sea mi apoderado, D. ${ }^{n}$ Pedro Cevallos, Ministro que fué de mi Augusto Padre y Hermano; para lo qual lo substituyo en su lugar, dandole como por esta mi Carta le doy y otorgo el mismo poder y facultad, para que pueda igualmente promover, instar, pedir, y reclamar, ante dicha Suprema Junta, o ante mi Nacion junta en Cortes, la misma posesion de los derechos que por Ley me pertenezcan, ácuyo fin remito la presente escrita y firmada de mi mano, y sellada con mi Real Sello. Dada en el Real Palacio del Rio de Janeiro á los 30 de Diciembre de 1809. 


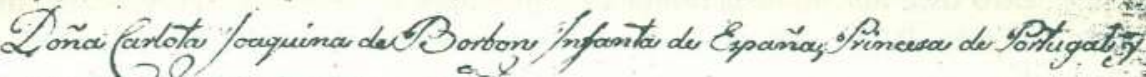
Orit fer fa fa

decomail f. f. $\ell^{\alpha}$, है

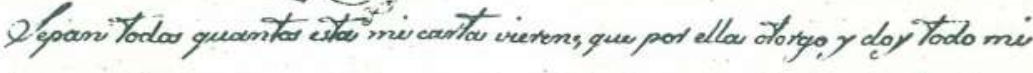

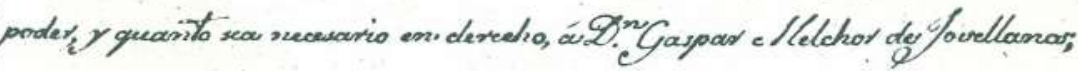

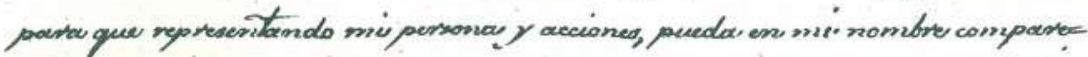

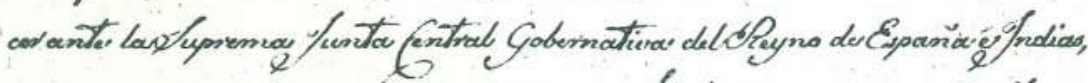

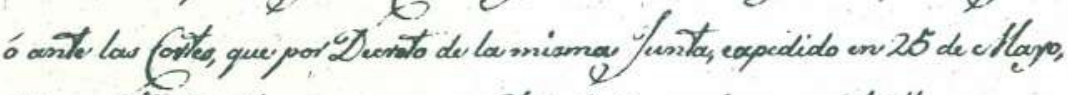

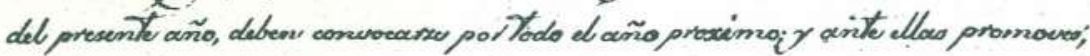

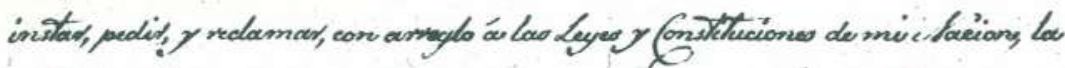

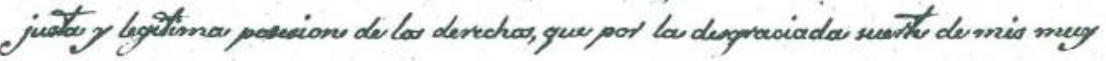

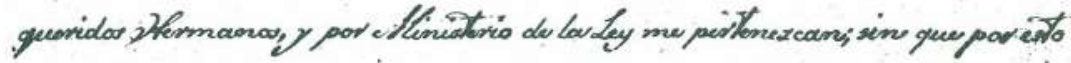

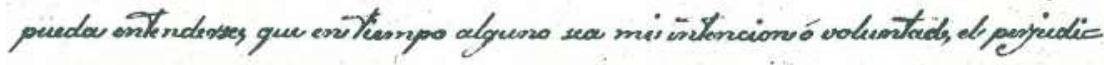

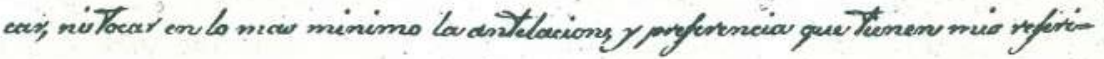

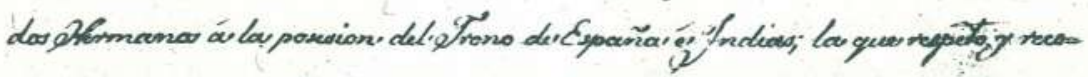

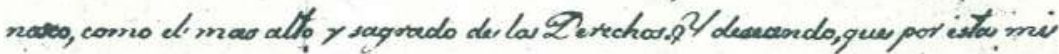

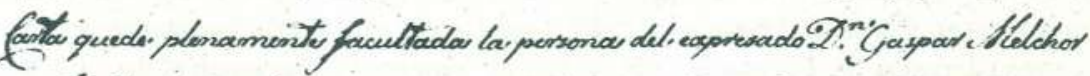

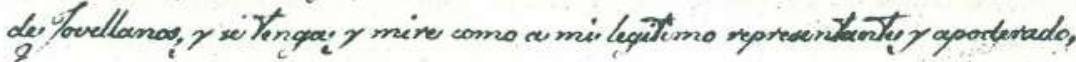

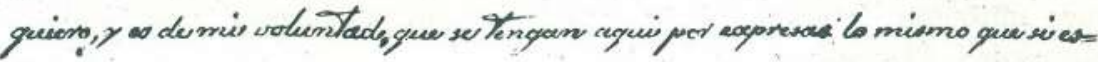

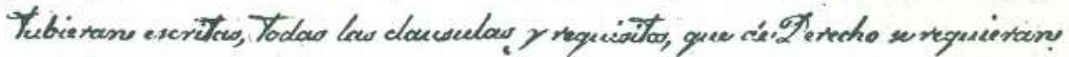

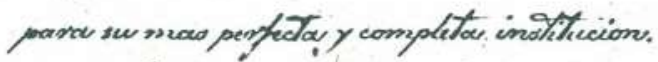

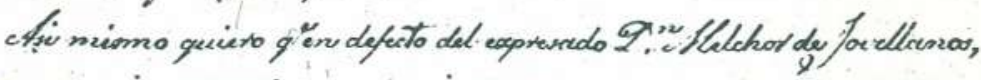

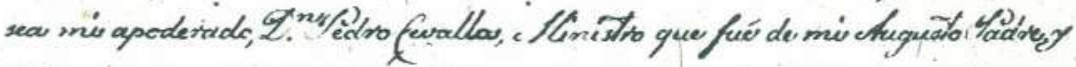

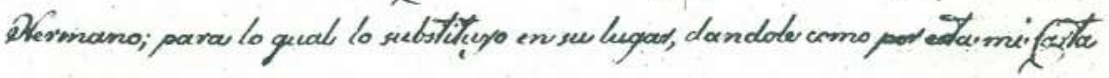

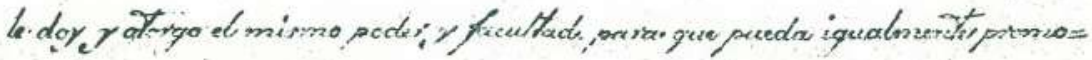

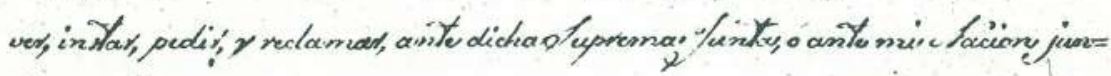

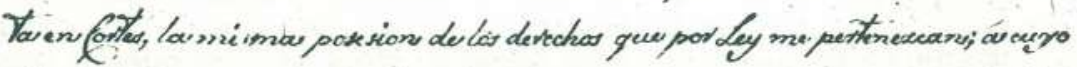

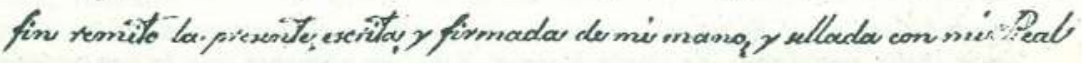

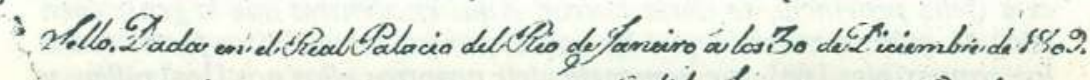

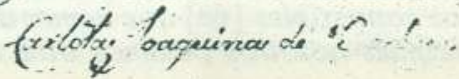


Esto dice mucho de la honradez y providad de Jovellanos. Perseguido durante el reinado de Carlos IV, una hija de éste - tan temperamental como Carlota Joaquina - le concedía plenos poderes para que la representara en asunto tan delicado como la sucesión. Hemos de tener en cuenta, como queda dicho, que Carlota Joaquina necesitaba su apoyo; pero no podemos ignorar que jamás le hubiera concedido tan amplio poder de no tener en él absoluta confianza. Incluso, como se ha visto, lo prefería a Cevallos. Sabía muy bien que Jovellanos jamás abusaría de dicho poder, y si no lo aceptaba se lo haría saber así.

Las tres cartas de 1812 se refieren a la situación de Cataluña durante la guerra de la Independencia. ${ }^{5}$ Escritas por una persona analfabeta - lo que requiere actualizar su ortografía para hacerlas inteligibles - tienen la ventaja de una gran sinceridad. $\mathrm{Su}$ autor es Francisco Presas, hermano de José Presas. Éste fue secretario de Carlota Joaquina, en Río de Janeiro, desde noviembre de 1808 a marzo de 1812. Citado por muchos, aunque desconocido por casi todos, José Presas fue una figura de primordial importancia para entender lo que la crítica ha llamado Carlotismo. En Río de Janeiro, primero, y en España, después, dirigió la campaña en pro de las aspiraciones de Carlota Joaquina al trono de Fernando VII, y fue el responsable de muchas de las intrigas que en ese sentido se llevaron a cabo en las Cortes de Cádiz, como trataremos de probar en un futuro libro que - junto con una riquísima correspondencia - será publicado por la editorial de la PUCRGS.

Cardona 10 de junio de 1812

Mi más querido y adorado hermano:

Son muchas las que te tengo escritas $y$ de ninguna he merecido respuesta, lo que extraño mucho y me hace estar con mucho cuidado de que no hayas tenido algún encuentro malo. No tendré un punto de alegria hasta que sepa cómo te encuentras. Ya sabes que somos las únicas alhajas, yo y tú, que hemos quedado de nuestros amados padres, porque de nuestro hermano Roque de nada nos podemos confiar, porque parece que se hace independiente de todos nosotros, y de nuestra hermana Marianita tiene bastante trabajos para poder vivir ellos. Porque si tu vieras los trabajos que estamos pasando en esta ifeliz provincia, te daria horror. Aqui encuentras que la gente caen [sic] de miseria muertos por las calles, porque los malditos futres todos los comestibles [de] que hemos de vivir nosotros ellos nos [los] pillan, y después nosotros pasamos otra vez por onde [sic] han pasado ellos y 
ponemos la hambre en aquel pais. $Y$ todo quien lo paga es el pobre paisano. Te digo que te tordirias [sic] el ver del modo que estamos en esta provincia desgraciada. Pero siempre los catalanes guardamos el mismo entusiasmo que al principio que entraron ellos en España. Aqui veras unos niños de doce y trece años que ya van detrás de los franceses con sus carabinas lo mismo que [si] cazasen conejos por los bosques. Ellos no pueden ir de ciento en ciento, porque lo mismo es salir de las plazas que ya no vuelven [a] entrar. Esto lo hacen los paisanos de los mismos pueblos. Matan más franceses los paisanos que no las tropas, porque ellos los matan dentro de sus casas mismas y nosotros siempre hemos de batirnos en el campo.

Ahora hemos tenido una acción muy favorable para nosotros, que salieron dos mil enemigos de dentro de Barcelona y el Mariscal de Campo D." Pedro Sarsfield los hizo una grande emboscada con su división, entre el puente de Molinos del Rey y San Andrés de Pellaga, y así que los tuvieron cortados salió la división del medio del bosque y los derrotaron perfectamente, que de los dos mil que salieron de Barcelona no volvió ni sólo uno. Y estos caballeros vanian a ponernos el sitio en la plaza de Cardona, pero han tenido que retirarse todas las demás tropas que nos tenian rodeada esta plaza, que habia el número de quince mil infantes y ochocientos caballos. Pero esta pérdida que han tenido de los de Barcelona los ha llamado la atención y nos han levantado el sitio de esta plaza, que ya hacia pensamiento de ir otra vez prisionero. Lo he estado cuatro veces, y esta habia estado cinco. $Y$ ahora han tenido los señores futres que retirarse dentro de las plazas porque hubiéramos acabado con todos ellos y se están alli dentro muriéndose de hambre, y nosotros nos mantenemos enfrente de todas las plazas que están ellos dentro. Pero tememos mucho de que venga algún refuerzo de dentro de Francia, que si no venian [sic] tropas de Francia en este verano quedariamos libres de todos estos malditos tiranos. Pero si vienen refuerzos nos van amolarnos [sic]. Vamos a quedar sin gente. [En] la Cataluña ya no encontrarás un mozo bueno para las armas, que esto es lo más sensible de todo. No digo más. Manda a tu amado hermano Francisco Presas.

P.D. No sé si habrás recibido una carta duplicada [?] pidiéndote si podrías alcanzar de la princesa Doña Carlota el empleo siguiente: el empleo que te pide este verdadero amigo mio es el alcanzar la gracia de ser director general de la provisión de utensilios. Ahora ya lo es, sino que interino; y ello, si pudiera ser, valdria ser en propiedad. Es favor que espero de ti que lo harás presente a tu ama, porque deseo servir a este amigo que me hace las funciones de padre, porque me ha sacado de muchos apuros y no sé como pagarle los beneficios que tengo recibidos de él. En todo cuanto puedes pensar me ha favorecido. Veas si me quiere este sujeto que por todas partes que vaya me ha dado letras para cobrar dinero, y me tiene dicho que no quiere que padezca habre mientras sea posible el poderme dar auxilio él. Ahora he tenido una enfermedad y él me ha favorecido en todo cuanto ha podido [aquí falta algo].

Hermano, me olvidaba en esta pensar que estoy con mucha necesidad. Si puedes favorecerme de algún dinero, te lo estimaria bastante, porque las dos onzas que me enviaste las he dado a nuestra hermana para poderse alimentar, porque están padeciendo mucha necesidad $y$ al mismo tiempo mantiene al hijo de nuestro hermano Gerónimo. Y si puedes enviarme alguna cosita para hacerme uniforme, 
que he mudado de regimiento y tengo que ir lo mismo que los demás oficiales. Ahora estoy en el regimiento de Barcelona. Ha cinco meses que estoy en él y me deben cuatro de pagas. Puedes pensar del modo que hemos de vivir, con mucha economía.

Las cartas que me escribas las dirigirás al Cuartel General de Cataluña, a D. ${ }^{n}$ Ramón Feliu y Binals, director de la provisión de utensilios, que fácilmente las recibiré, porque no se mueve nunca de Cuartel General y él me las remitirá siempre a mí, que él sabe siempre mi paradero.

José Presas ya no se encontraba en Río de Janeiro, de donde salió a primeros de abril de 1812 y llegó a España los primeros días de julio del mismo año. Ocupado en ganar a los políticos españoles para la causa de D. ${ }^{a}$ Carlota, no comunicó su llegada a la familia, como lo prueban las dos cartas siguientes. La primera no lleva fecha, pero es posterior al $22 \mathrm{de}$ julio de 1812, puesto que da la noticia de la batalla de Arapiles.

\section{Hermano:}

Aqui te participaré todas las demás noticias que pasan en este principado. Ha venido ya el feliz día que han publicado la nueva Constitución, y a más de esto la derrota de Marmot, que ha perdido 50.000 hombres, y a más otra derrota que es la de [?], en el regato de Valencia, que ha perdido 6.000 hombres, $y$ dicen que en estas horas [en] Valencia han entrado los nuestros. Lo que si [es] cierto [es] que en este principado han quedado muy pocos futres porque todos se han marchado a reforzar al conde de [?] y a recibir al infringido José Botella, que se ha escapado de Madrid y dicen que viene en dirección a Cataluña. Lo estamos aguardando con muchos deseos, para ver si aqui dejará sus costillas.

Los que salieron el 23 de Barcelona para ir [a] auxiliar a Valencia en Molinos del Rey empezamos a diezmarlos. Alli pagaron los derechos señalados que tiene $S .{ }^{m}$ [sic]. Quedaron en nuestro poder mil doscientos cincuenta prisioneros, y más de quinientos muertos quedaron en el mismo puente de Molinos del Rey. Ya puede aguardar el conde de [?] el refuerzo que le bajaba de Cataluña. A esta división que no va a reforzarlo los [sic] obligamos a que se encerraran otra vez dentro de Barcelona, y ahora los tenemos alli que no sale ni uno de dentro. Ya los tenemos acobardados en esta maldita [?]. Lo malo será no poder pillar [a] aquel maldito Napoléon, pero algún día caerá en nuestras manos. Si Dios le puede dar la suerte de caer en manos nuestras ya quedará satisfecho de los españoles. La lástima será que los mismos franceses lo matarán antes, o si no ya habría [aquí dos palabras ininteligibles].

Otra función buena con el brigadier doctor Rovira en el grau de otot [sic]. Los enemigos lo atacaron y él se mantuvo firme en el punto que le habia mandado el general que sostenga [sic], y fue tanta la pérdida que tuvo el enemigo, que de los que lo atacaron no se volvió ni sólo uno para llevar el aviso de lo que lo habia pasado. Son 
cuatrocientos los prisioneros y los muertos serán algunos 200. La pérdida nuestra son 50 entre muertos e heridos.

No hay más noticia para ahora. Manda a tu hermano que te quiere de corazón, Francisco Presas.

[P.D.] Escribeme cuanta noticia tengas buena.

Cardona, 2 de setiembre de 1812

Amado hermano:

Con vivo dolor te participo la fatal noticia de la muerte de mi amado amigo $D .^{n}$ Ramón Feliu. He sentido mucho su muerte porque no tenía otro amparo y consuelo que era él [sic], y por lo mucho que me queria el a mi y yo a él. No puedo pagarle los beneficios que tengo recibido del difunto $D .{ }^{n}$ Ramón porque me ha sacado de algunos apuros muy malos, porque cuando no tenía qué comer ya tenía onde [sic] recurrir que no me faltaba nada de todo cuanto le pedia. Ni que hubiese estado hijo suyo no hubiera hecho más de lo que ha hecho por mi. Creas bien, hermano, que [he] perdido una de las personas que yo tenía más confianza. Pero no hay remedio. Dios lo quiere asi $[\mathrm{y}]$ no nos podemos oponer a lo que dispone el Señor. El lo hace $[\mathbf{y}]$ sabrá por qué es un camino [aquí falta alguna línea] voluntad suya.

Hermano, ya pienso que habrás recibido dos cartas duplicadas [?], que la una era mía y la otra del referido difunto $D^{n}$ Ramón, que te pedia en ella que mires [sic] de alcanzarle por los medios de tu ama, la Señora Princesa del Brasil, lo que si no tienes alcanzado nada de lo que te pedía dicho difunto no tienes que mover nada porque no serviría de nada. El trabajo que emplearías en pedirlo ya tiene todos los asensos hechos.

Hermano, que asi como habias de hacer las diligencias de empeñarte por este $S^{r}{ }^{r}$, que ahora te empeñes a hacerlas para tu nabot de alcanzarle el medio sueldo de su difunto padre, que yo no puedo alcanzar nada. Ya tengo tres memoriales hechos a Su Majestad y no he podido lograr nada, y puede que tú alcanzaras más fácilmente por parte de tu ama lo que tan gustosamente pido. Ya sabes del modo que se ha portado nuestro hermano difunto, que ha sacrificado él y toda su familia y bienes para defender la justa causa que estamos defendiendo. $Y$ no me parece justo que el nuestro [sic] nabot quede desamparado del todo. Ya que tiene perdido su padre [sic], al menos que pueda alcanzar el medio sueldo de su difunto padre [sic] para mantenerse a las escuelas y seguir la misma carrera que tenía su padre. Espero de tu [ ?] bondad que no perderás tiempo en hacerlo presente a nuestra amada princesa doña Joaquina de Borbón, y pienso que ella no tendrá inconveniente de empeñarse en una cosa tan justa como es esta. Ya ves que yo por mi parte hago todo cuanto puedo en favor de nuestro nabot; que estoy padeciendo necesidad solamente para dar de comer a nuestra hermana Maria y a este infeliz niño. Ya puedes considerar si yo hago cuanto puedo por ellos [que] cuanto tú me remitistes aquellas dos onzas se las entrego [sic] a nuestra hermana para que remediasen un poco de sus 
necesidades, porque ellos han quedado hechos unos miserables, porque estos malditos futres todo cuanto tenían lo han pillado. Hasta un día se habian llevado [al] hijo de nuestro hermano Gerónimo, que en paz descanse, diciendo que hasta tanto que yo me presentase a las órdenes del maldito general no volverian al pobre niño. Puedes pensar que sentimiento era el mio el ver que aquel infeliz inocente [ha]bia de padecer para mi; pero quiso Dios que lo volvieran otra vez a casa, pero me han dotado [sic] a mi de dos mil pesos el que me puede [sic] pillar. Pero esto nada me importa porque estoy contento de morir. Sólo la mía pase adelante. Yo pienso que acabaremos con todos ellos antes. No tendrán que pagar los dos mil pesos por la presa mia. Ya hemos logrado que en Lérida hemos [sic] muerto más de dos mil quinientos dellos [sic], y el castillo volado la noche del veintisiete de julio. A las doce de la noche volamos el castillo y todos cuantos habia dentro volaron. Fue un contento. Puedes pensar que voladura sería aquella cuanto [sic] las piezas de artillería de veinticuatro fueron a parar en esta parte del río, y la ciudad más de la mitad fue a tierra. Se dice que entre paisanos y franceses han muerto más de 8.000 almas, pero quien pegó más el pan fueron los paisanos. De francese murieron 2.000. Francisco Presas.

\section{PUCRS}

Departamento de História

Porto Alegre, Brasil

\section{NOTAS}

${ }^{1}$ La carta figura con el número 6 en los registros de correspondencia de D. ${ }^{\text {a }}$ Carlota Joaquina. Son cuatro grandes volúmenes sin numerar. Cada uno lleva el título de Libro de Registro Secreto de los Negocios que S.A.R. la Infanta de España Doña Carlota Joaquina de Borbón, Princesa de Portugal, etc., etc., tuvo a bien entablar con los Virreyes, Autoridades y Pueblos de las Americas e Islas Filipinas... Se encuentran en el archivo particular del Príncipe D. Pedro de Orleans y Braganza, a cuya gentileza debo este dato, que puso dicho archivo a mi entera disposición.

${ }^{2}$ Archivo Imperial del Brasil (Petrópolis), II-POB-22.2.809-CJ.P.m 1-21. Sólo la última palabra y la firma son de Jovellanos. Con esa misma fecha contestó al general Sebastiani, negándose a pasarse al lado de José Bonaparte.

${ }^{3}$ Archivo Historico Nacional de Madrid, Jesuitas, legajo 751, expediente 3. Salvo error, reproduciomos este documento al pie de la letra. Al final, lleva una nota que dice: "S. ${ }^{\mathrm{r}} \mathrm{D} .{ }^{\mathrm{n}}$ Angel. Este memorial ha venido dentro del esped. ${ }^{\text {te }}$ de los Estudios R. ${ }^{\text {es }}$, que ha enviado vm. con los papeles á la firma."

${ }^{4}$ Archivo Imperial de Brasil (Petrópolis), II-POB-24.4.809-CJ.P. do 1-8.

${ }^{5}$ Ibid., I-POB-10.6.812-Pre.c 1-4. Mi profundo agradecimiento al Director del Archivo Imperial, Profesor D. Lorenço Luís Lacombe, por las infinitas atenciones de que me hizo objeto durante mi investigación. 